\title{
Peri- and post-operative management of the "high-risk" surgical patient. an audit of practice in a large district general hospital
}

\author{
L Winslow ${ }^{*}$, L Bridge \\ From ESICM LIVES 2015 \\ Berlin, Germany. 3-7 October 2015
}

\section{Intr}

In 2011, the National Confidential Enquiry into Patient Outcome and Death (NCEPOD) published a report, "Knowing the Risk," [1] which reviewed data regarding peri-operative management of the high risk surgical population and subsequently produced recommendations in aim to improve outcomes in this patient population.

Of particular focus, recommendations included; clear documentation of operative mortality risk, to use perioperative cardiac output monitoring with CardioQ technology, as supported by NICE Medical Technology guidance 3 [2] and to provide higher-level care, with Critical Care input, post-operatively.

\begin{abstract}
Aim
This study aimed to audit clinical anaesthetic practice at a large district general hospital (DGH) against those recommendations outlined in the NCEPOD 2011 report, regarding the management of high risk surgical patients.
\end{abstract}

\section{Methods}

Case notes were used for retrospective data collection. Patients undergoing emergency surgery between JanuaryMarch 2013 and January-March 2014 were identified. From these, high-risk patients were selected for inclusion in the audit. For the purpose of this audit, high-risk patients were defined as those older than 65 years and undergoing emergency laparotomy. Data included demographic details, documentation of risk, peri-operative haemodynamic monitoring used, 30-day survival and involvement of Critical Care post-operatively. These data were collated and compared between 2013 and 2014, identifying any interval improvement, and with the national prospective data outlined in the NCEPOD report.

\section{Results}

33 and 23 patients were identified as undergoing highrisk surgery in 2013 and 2014, respectively.

NCEPOD data identified arterial lines; central lines and cardiac output monitoring were used in $27 \%, 14 \%$ and $5 \%$, in high-risk patients, respectively. In this audit, these figures were $50 \%, 36.1 \%$ and $2.8 \%$, in 2013 , and $60.9 \%, 26.1 \%$ and $34.8 \%$, in 2014 , respectively.

In this audit, $69 \%$ and $65 \%$ of "high-risk" patients were referred to higher-level care in 2013 and 2014, respectively. Of these, 85\% (2013) and 90\% (2014) had a clearly documented plan from higher-level care, whether that be admission to HDU or outreach plan. The overall admission rates to higher level care were $47.2 \%$ and $65.2 \%$ in 2013 and 2014, respectively. This is comparable to the $22.1 \%$ seen in the NCEPOD data.

\section{Conclusions}

Comparison between 2013 and 2014 data suggests perioperative care is improving year-on-year after publication of this NCEPOD report. However, there is a need for further improvement in peri-operative care to fully comply with NCEPOD recommendations.

\section{Published: 1 October 2015}

\footnotetext{
References

. Knowing the Risk. A review of peri-operative care of surgical patients. NCEPOD 2011.

2. CardioQ-ODM oesophageal Doppler monitor. NICE Medical Technology Guidance 2011, 3, March.
} 
doi:10.1186/2197-425X-3-S1-A241

Cite this article as: Winslow and Bridge: Peri- and post-operative

management of the "high-risk" surgical patient. an audit of practice

in a large district general hospital. Intensive Care Medicine Experimental 2015 3(Suppl 1):A241.

\section{Submit your manuscript to a SpringerOpen ${ }^{\mathcal{O}}$ journal and benefit from:}

- Convenient online submission

- Rigorous peer review

- Immediate publication on acceptance

- Open access: articles freely available online

- High visibility within the field

- Retaining the copyright to your article

Submit your next manuscript at $>$ springeropen.com 